\title{
Structure analysis of goose immunoglobulin $Y$ Fc fragment
}

\author{
LEI JIANG, WEI-SHAN CHANG, HAO GUO, PENG SUN, XIU-MEI DAI
}

Shandong Agricultural University, Shandong China

\begin{abstract}
Objective: Goose immunoglobulin Y (IgY)-Fc fragment gene is cloned.

Material and methods: In order to obtain a certain length (106 bp) of constant domain gene, a pair of primer was designed according to the conserved nucleotide sequence of duck (CAA46322) and chicken (S00390) IgY-Fc fragment that was published by the GenBank. Special primers were designed by the Race method to amplify the 3'terminal cDNA.

Results: Goose IgY heavy chain C domain partially unknown gene is successfully cloned, and it is 782 bp. The full-length gene covers the Cu3 and Cu4 domains, i.e. Fc gene encoding 202 amino acids, the predicted molecular mass of $F c$ gene is $22.32 \mathrm{kDa}$. The deduced amino acid sequence of goose $F \mathrm{c}$ showed $89.6 \%$ and $65.3 \%$ identity with those of duck and chicken, respectively.

Conclusions: Conserved sequence amplification PCR combined with Race is effective in searching and isolating Fc gene of goose. It is successfully submitted to the GenBank; GenBank accession number is KC254644. The structure of goose IgY-Fc was analyzed using bioinformatics tools. In the 3D structure of goose IgY-Fc, the sequence identity is $64.29 \%$ to the template (chicken: 2 w59A).
\end{abstract}

Key words: goose, IgY-Fc fragment, structure analysis.

(Centr Eur J Immunol 2013; 38 (3): 299-304)

\section{Introduction}

Immunoglobulin $\mathrm{Y}(\operatorname{IgY})$ is the principal serum antibody in birds and reptiles, and an IgY-like molecule was the evolutionary precursor of both mammalian $\mathrm{IgG}$ and $\operatorname{IgE}$ [1]. The IgY heavy chain consists of four constant domains, and the Fc fragment mainly contains two constant domains on the C-terminal, the $\mathrm{Cu} 3$ domain and the Cu4 domain $[2,3]$. Immunoglobulin Y Fc fragment not only has the ability to activate the complement system, but also induces the binding of the antigen-antibody complex and the antigen-presenting cell through the Fc receptor (FcR). It can also promote the phagocytosis of the antigen-presenting cells to foreign antigens in the receptor-induced, and thus stimulate the cellular immune response of the body of specific antigens $[4,5]$. Fc receptors link the specificity of the adaptive immune system with the effector mechanisms of innate immune cells [6]. Recently several avian IgY-Fc receptors have been identified, such as CHIR-AB1, a newly identified avian immunoglobulin receptor that includes both activating and inhibitory motifs and therefore classified as a potentially bifunctional receptor [7]. But the source animal of the research is chicken. Not too much in-depth study of goose in this field is done. Although the homology between the two species is high, there are still a lot of differences in their sequences. The nucleotide sequences and amino acid sequences of chicken and duck IgY have been assayed and submitted to the GenBank. The structure of the first nonmammalian Fc region of an antibody (chicken) has been determined [8].

In this study, we firstly cloned the goose IgY-Fc fragment gene and submitted the sequence to the GenBank. Then, we constructed a 3D structural model of goose IgYFc fragment through the fully automatic procedure of the SWISS-MODEL server. The results of the study will provide the basis for understanding the differences of IgY-Fc between avian and mammalian species. It can also lay the foundation for the study of goose IgY-Fc with its receptors. 


\section{Material and methods}

\section{Sample collection and tissue preparation}

The domestic geese were purchased from a goose farm, Taian, China. Spleens were harvested and frozen in fridge $\left(-20^{\circ} \mathrm{C}\right)$.

\section{Total RNA isolation and synthesis of cDNA}

Total RNA samples were extracted from spleens using Trizol (TransGen) and the cDNA pool was obtained using the PrimScript RT reagent Kit (TaKaRa).

\section{RT-PCR, 3'Race and sequencing}

A pair of homologous primers (Table 1A) was designed with DNASTAR 5.0 software in the conserved region (Fig. 1) of the duck (GenBank: CAA46322) and chicken (GenBank: S00390). All primers used in this study are listed in Table 1. With the primers, a cDNA fragment was amplified by RT-PCR using the first strand cDNAs as templates. The PCR reaction was performed under the following conditions in a thermal cycle: initial denaturation at $94^{\circ} \mathrm{C}$ for $5 \mathrm{~min}$; 30 cycles of denaturation at $94^{\circ} \mathrm{C}$ for $30 \mathrm{~s}$; annealing at $58^{\circ} \mathrm{C}$ for $30 \mathrm{~s}$ and extension at $72^{\circ} \mathrm{C}$ for $10 \mathrm{~min}$. PCR products were analyzed by electrophoresis in $1 \%$ agarose, and purified by Agarose Gel DNA Extraction Kit (Shanghai Sangon Biotech Co., Ltd.). The products were cloned by Peasy-T1 (TransGen) and sent to Shanghai Sangon Biotech Co., Ltd. for sequencing. According to the results of sequencing, two pairs of specific primers (Table 1: 3'Race 1 and 2) were designed. In the 3'Race, Nested PCRs were performed with the first pair of 3'Race and the second pair for the second round. PCR products were analyzed

Table 1. Conserved sequence amplification PCR and 3'race products using forward and reverse primer sequences

\begin{tabular}{ll}
\hline Primer name & Primer sequences \\
\hline A & 5'-cagagctgcagccccatc-3'(f) \\
\cline { 2 - 2 } & 5'-cgctgggcaggttgaccac-3'(s) \\
\hline 3'Race1 & 5'-cagctgcagccccatccag-3'(f) \\
\cline { 2 - 2 } & 5'-ctagcgtcgctcctgactcgtttttttttttttttt-3'(s) \\
\hline 3'Race2 & '-gcctctacgtccgccagga-3'(f) \\
\hline & 5'-ctagcgtcgctcctgactcg-3'(s) \\
\hline
\end{tabular}

by electrophoresis in $1 \%$ agarose, then purified and cloned into Peasy-T1, detected and sequencing was performed.

\section{Multiple alignment and phylogenetic sequence analysis}

The nucleotide sequence of goose IgY-Fc fragment, along with that of avian and several mammalian species from GenBank, were aligned by DNAMAN software. Phylogenetic analysis was made using DNAMAN5.2 software. Sequence analysis of the predicted goose IgY-Fc protein translated from the nucleotide sequence of goose IgY-Fc fragment was performed using the NCBI and ExPaSy software. Signal peptides were predicted using the SignalP 3.0 server. The domain structure of the caprine protein was analyzed on the SMART server. The SWISS-MODEL server was used to model the protein $3 \mathrm{D}$ conformation.

\section{Results}

\section{Molecular cloning and analysis of goose IgY-Fc}

A cDNA fragment of goose IgY heavy chain of $106 \mathrm{bp}$ (Fig. 2) was obtained from single RT-PCR that was identified from the spleen cDNA library of domestic goose which are homologous to duck and chicken. Based on this sequence, the 3'terminal cDNA was cloned using 3'Race PCR. After splicing, a 782 bp fragment of IgY heavy chain was obtained. It covers the $\mathrm{CH} 3$ and $\mathrm{CH} 4$ region, i.e. Fc gene. It encodes a protein 202 amino acids in length.

\section{Analysis of the translated amino acid sequence of IgY-Fc}

The deduced amino acid sequence has an estimated isoelectric point and $\mathrm{Mr}$ of 6.47 and $22.32 \mathrm{KD}$, respectively. The number of negatively charged residues (Asp $+\mathrm{Glu})$ in the sequence is 19 . The total number of positively charged residues $(\mathrm{Arg}+\mathrm{Lys})$ is 17 , indicating that the protein has an overall negative charge. The $\mathrm{N}$-terminal of the sequence considered is I(Ile) residue. The instability index (II) is computed to be 48.53 , which classifies the protein as unstable. The aliphatic index is 74.70 and the grand average of hydropathicity (GRAVY) is -0.168 . The number of the phosphorylation sites predicted is 12 (Ser: 7 Thr: 4 Tyr: 1). No signal peptide was identified by the SignalP software. The secondary structure of the protein was predicted to be main-

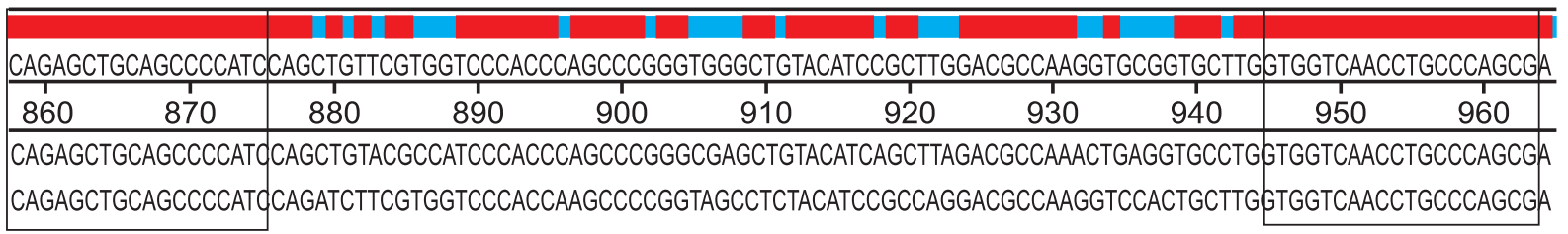

Fig. 1. Conserved nucleotide sequence of duck and chicken IgY-Fc. The sequence in the box is highly conserved, and it is used as forward and reverse primer 


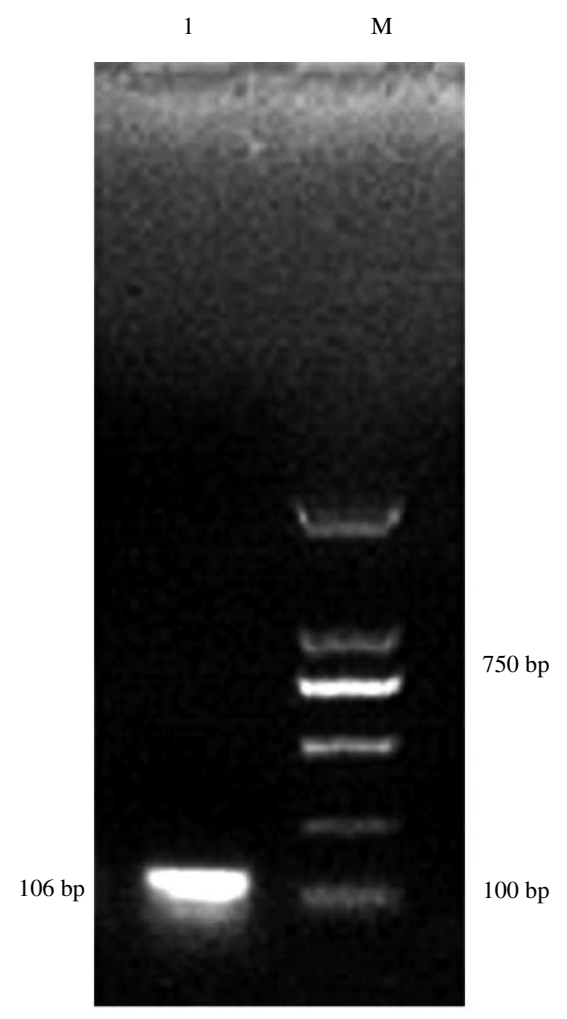

Fig. 2. RT-PCR amplification result of the conserved sequence

ly random coil, separated by an extended strand and $\alpha$-helix (Fig. 4).

The SMART domain architecture analysis results indicated that goose Fc has two domains. The first domain starts position 16 and ends position 90 . The second domain starts position 121 and ends position 198. The predicted two domains have a structure that is similar to IGc1 domain which is classical of Ig-like domains resembling the antibody constant domain.

\section{Alignment and phylogenetic analysis}

The deduced amino acid sequence of IgY-Fc was compared with those of the several avian and mammalian species using DNAMAN (Fig. 5). The alignment analysis showed that goose Fc fragment shared $90.0 \%$ and $65.3 \%$ identity with those of duck (CAA46322) and chicken (S00390), and 36.0$41.0 \%$ identity to mammalian counterparts. The arrows

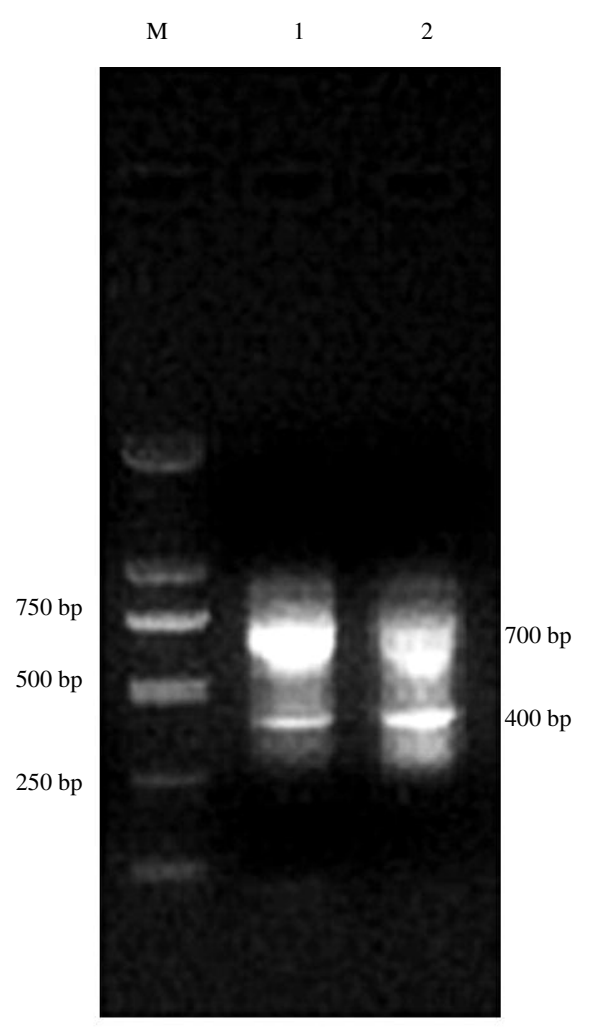

Fig. 3. Result of 3'race amplification. About 700 bp size gene is the purpose gene

labeled amino acid residues in Fig. 6 were well conserved in avian and mammalian, yet goose IgY-Fc Gly ${ }^{193}, \mathrm{Thr}^{200}$ were different from chicken's equivalent amino acids. The phylogenetic tree was constructed from the deduced goose IgY-Fc and the $\operatorname{IgG}(\mathrm{Y})$ sequences from avian and mammalian with software DNAMAN 5.0. The result revealed the highest homology was with duck, and avian IgY-Fc formed a monophyletic group distinct from mammalian IgG-Fc (Fig. 6).

\section{Predicted 3D structural model of goose Fc fragment}

The fully automatic procedure on the SWISS-MODEL server was used to construct a 3D structural model of goose IgY-Fc fragment. The homology modeling revealed that this segment was similar to that of the avian (chicken) IgY-Fc in the Protein Data Bank (PDB:2w59A:349-557).

Not too many differences were found in the number of amino acids and orientation in the goose IgY-Fc frag-

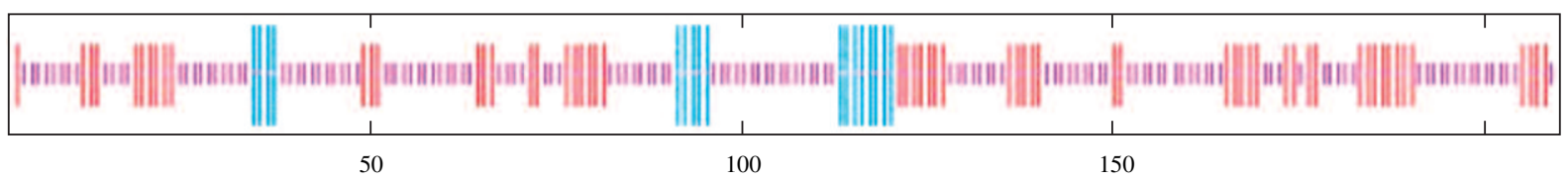

Fig. 4. The predicted secondary structure of the goose IgY-Fc amino acid sequence. The network secondary structure prediction method was used. The blue line represents $\alpha$-helix, the red line represents extended strand, and the purple line represents random coil 

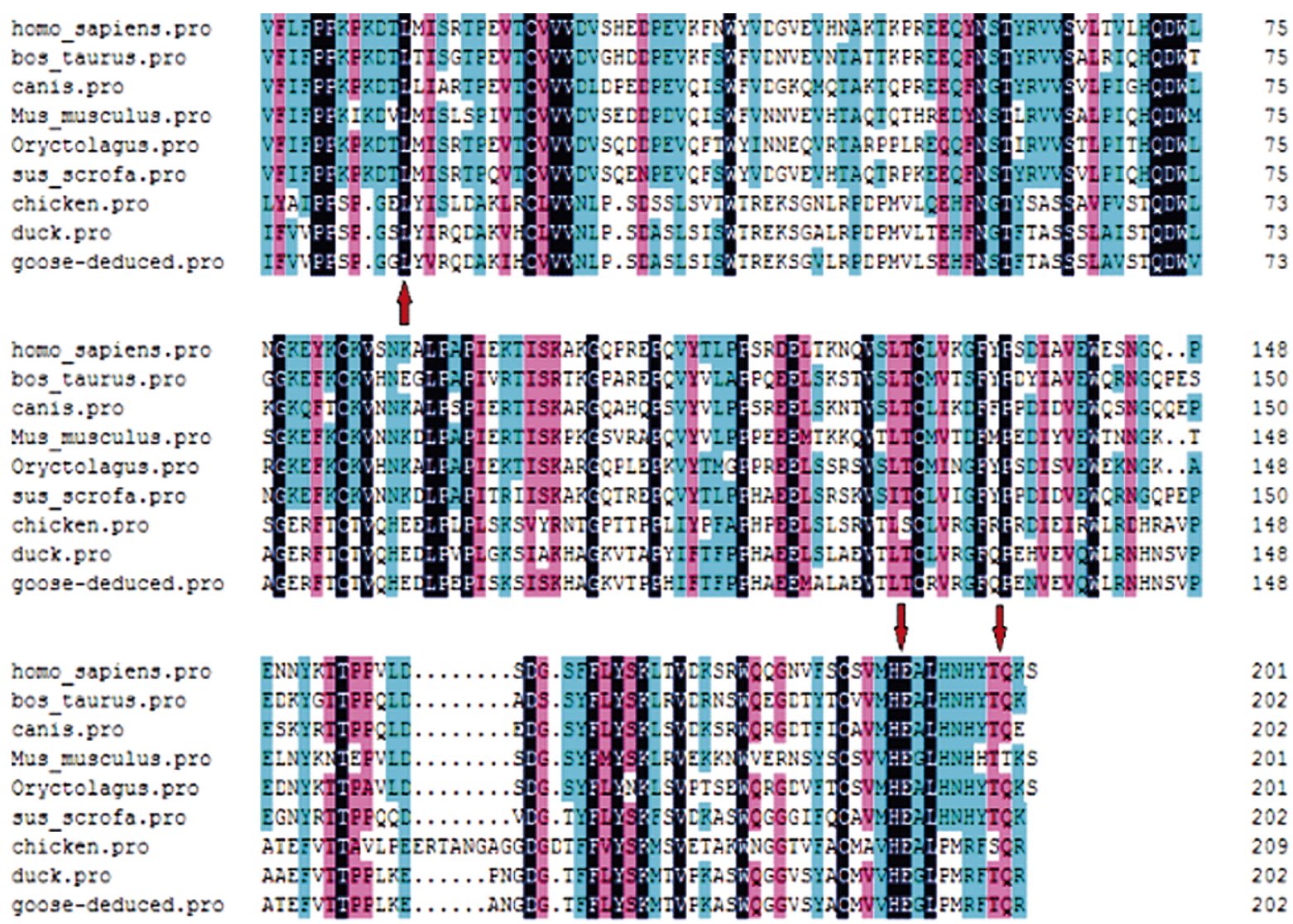

Fig. 5. Comparison of the predicted amino acid sequences of goose, duck, chicken IgY-Fc. The dark shadow reveals the conserved amino acid residues. Semi-conserved residues are marked in pink shadow. The arrows indicate the FcRY(FcRn)-binding site in $\operatorname{Ig} \mathrm{Y}(\mathrm{G})[9]$

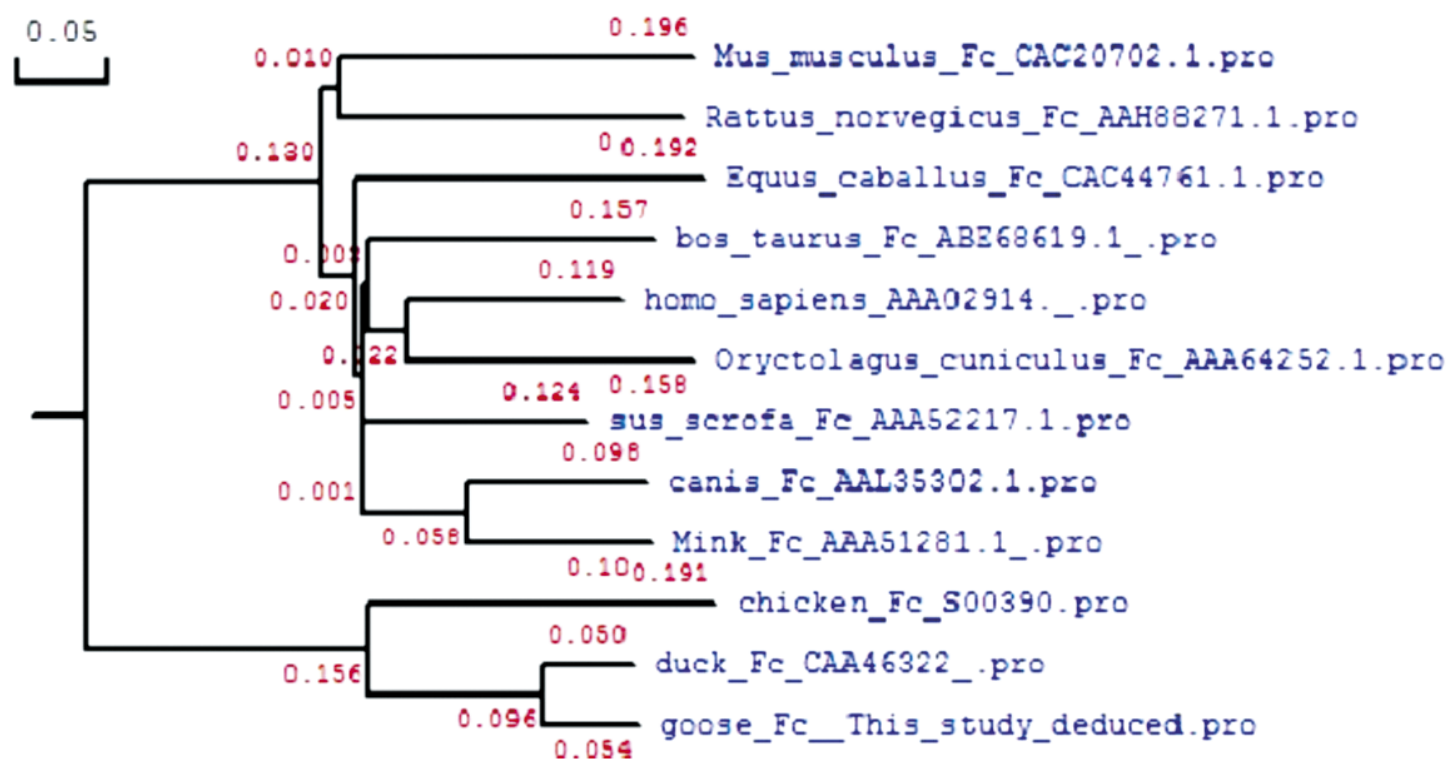

Fig. 6. Phylogenetic tree of $\operatorname{IgG}(\mathrm{Y})$ amino acid sequences of three poultry and several mammalian species. The GenBank numbers of the compared sequences are in the Figure which are behind the name of the different species 
A

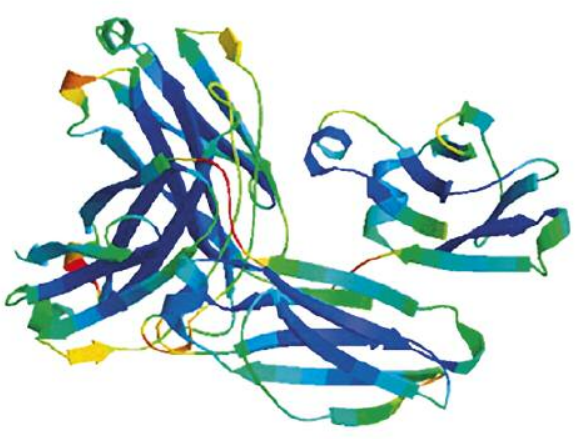

B

\begin{tabular}{|c|c|c|c|c|c|c|}
\hline $\begin{array}{l}\text { TARGET } \\
2 W 59-1\end{array}$ & $\begin{array}{l}46 \\
397\end{array}$ & $\begin{array}{l}\text { PDPMVLSRHP } \\
\text { pdpmVlqehf }\end{array}$ & $\begin{array}{l}\text { NSTptAssst } \\
\text { ngtyaasav }\end{array}$ & $\begin{array}{l}\text { AVSTQDWVAG } \\
\text { pvetqdwlag }\end{array}$ & $\begin{array}{l}\text { ERPTCTVQHB } \\
\text { exftetvqhe }\end{array}$ & $\begin{array}{l}\text { DLPBPISKSI } \\
\text { elplpIakav }\end{array}$ \\
\hline $\begin{array}{l}\text { CARGET } \\
\text { ?W59_1 }\end{array}$ & & $\begin{array}{l}00000 \\
00000\end{array}$ & $\begin{array}{l}00000000 \\
00000000\end{array}$ & $\begin{array}{l}\approx \text { hhhhh } \\
\approx \approx \mathrm{hhhhh}\end{array}$ & $\begin{array}{l}000000 \\
000000\end{array}$ & $\begin{array}{l}00000 \\
00000\end{array}$ \\
\hline
\end{tabular}

\begin{tabular}{|c|c|c|c|c|c|c|}
\hline $\begin{array}{l}\text { TAROET } \\
\text { 2W59_1 }\end{array}$ & $\begin{array}{l}96 \\
447\end{array}$ & $\begin{array}{l}\text { SKHAGKVTPP } \\
\text { YrntgPtTPP }\end{array}$ & $\begin{array}{l}\text { HIFTEPPHAE } \\
\text { IIYPI AphPe }\end{array}$ & $\begin{array}{l}\text { EMALAEVTLT } \\
\text { elOlNXVE } 10\end{array}$ & $\begin{array}{l}\text { CRVRGFOPEN } \\
\text { clvrgfrprd }\end{array}$ & $\begin{array}{l}\text { VEVOWLRAHR } \\
\text { le1rwl rdhx }\end{array}$ \\
\hline $\begin{array}{l}\text { TARGET } \\
2 \text { W59 1 }\end{array}$ & & & 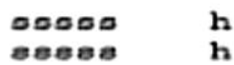 & 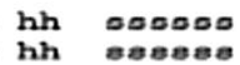 & 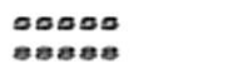 & 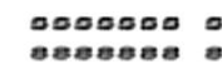 \\
\hline
\end{tabular}

TARGET 146 SVDATRFVT- -TDDLKRAN ODG-TDDLYS KMTVDKASWO GGVSYACMVV 2w59_1 497 avpatefvtt avlpeertan gdgdtffryo kmovetakwn ggtvfacmav

TARGET

2w59-1

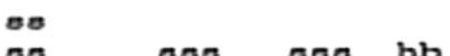

88880 880808hhhh 8808080

00 000 000 hh 00000000000hhh 000000

$\begin{array}{ll}\text { TARGET } & 192 \\ 2 \text { W59-1 } & 550\end{array}$

HEGLPMRFTQ RPLQK -..- - IFVVPPS PGGLYVRODA KIHCVVVNLP healpenxfeq relqk-qapi q--lyaippo pgelyialda klrelvvnlp

TARGET

2w59-1

- 0000000

$\bullet$

a aมa aอง

$\begin{aligned} \text { anh } & \text { hhh } \\ \text { a asa } & \text { hhhh }\end{aligned}$

000000000

SDASLSISWT REKSOVLRED PMVLSEHENS TVTASSSLAV STODWVAOER odoslovtwt rekegnlrpd pmvlqehfing tyoasoavpr otgdwloger

$\begin{array}{ll}\text { TAROET } & 234 \\ 2 \text { W59-1 } & 379\end{array}$

TARGET

2w59_1

a $a \boldsymbol{a} \boldsymbol{a}$

อง $a \boldsymbol{a}$

องaองaอง hhhh

easea 80

exese

o800808080 hhhh

Fig. 7. The 3D structure of goose IgY-Fc based on homology modeling. (A) The goose IgY-Fc amino acid sequence was mapped onto the crystal structure of the avian (chicken) IgY-Fc in the Protein Data Bank (PDB:2w59A:349-557) using SWISS-MODEL. (B) "S" indicates the residues that form the "bend"; and " $h$ " indicates the residues that form the " $\alpha$-helix"

ment of the $3 \mathrm{D}$ structures. However, for example, at corresponding positions in the two structures, there were two "bend" and one $\alpha$-helix between amino acids 504-515 in the avian IgY-Fc, but there was no bend or $\alpha$-helix in goose IgY-Fc. Perhaps the absence of three residues at positions $155-158$ in goose IgY-Fc caused the difference. But it was basically the same in both three-dimensional structures. They would have the same function. So the 3D structural analysis may provide the basis for studying the relationship between the structure and function of the IgY$\mathrm{Fc}$ in the avian.

\section{Discussion}

The gene of Fc region antibody (chicken) of nonmammalian has been determined. The amino acid sequence of duck Fc showed $66.8 \%$ identity with those of chicken. Previous studies have reported that duck IgY failed to bind to chicken CHIR-AB1 [10]. It is likely that both chicken and duck IgY interact with their respective receptors in a broadly similar manner: the positive residue in the duck sequence being accommodated by a complementary site in the duck receptor, while other pairings 
remain identical [11]. The highest homology of goose IgY-Fc was with duck (89.6\%). In the 3D structure of goose IgY-Fc, the sequence identity is $64.29 \%$ to the template (chicken:2w59A). For the FcRY-binding site, goose's two amino acid residues differ from chicken's equivalent amino acids.

It was said that IgY transport ability into egg yolks can be enhanced by substitution of amino acid residues located on the $\mathrm{Cu} 3 / \mathrm{Cu} 4$ interface [12]. However, information about goose IgY-Fc and its receptors has not been available.

In this study, we isolated the goose IgY-Fc gene and used various bioinformatics tools to analyze the gene and predicted protein sequence. The nucleotide sequence was successfully submitted to GenBank; GenBank accession number is KC254644. The acquirement of the full sequence of goose IgY is underway in our lab. This study will provide the basis for understanding the differences of IgY-Fc between avian and mammalian species. It can also lay the foundation for the study of goose IgY-Fc with its receptors.

The authors declare no conflict of interests.

This work was supported by project J08LF60 of the Shandong (China) Provincial Department of Education.

\section{References}

1. Taylor AI, Beavil RL, Sutton BJ, Calvert RA (2009): A monomeric chicken IgY receptor binds IgY with 2:1 stoichiometry. J Biol Chem 284: 24168-24175.

2. Suzuki N, Lee YC (2004): Site-specific N-glycosylation of chicken serum IgG. Glycobiology 14: 275-292.

3. Parvari R, Avivi A, Lentner F, et al. (1988): Chicken immunoglobulin gamma-heavy chains: limited VH gene repertoire, combinatorial diversification by $\mathrm{D}$ gene segments and evolution of the heavy chain locus. EMBO J 7: 739-744.

4. Ferrone CR, Perales MA, Goldberg SM, et al. (2006): Adjuvanticity of plasmid DNA encoding cytokines fused to immunoglobulin Fc domains. Clin Cancer Res 12: 5511-5519.

5. Regnault A, Lankar D, Lacabanne V, et al. (1999): Fc $\gamma$ receptor-mediated induction of dendritic cell maturation and major histocompatibility complex class I-restricted antigen presentation after immune complex internalization. J Exp Med 189: 371-380.

6. Warr GW, Magor KE, Higgins DA (1995): IgY: clues to the origins of modern antibodies. Immunol Today 16: 392-398.

7. Arnon TI, Kaiser JT, West AP Jr, et al. (2008): The crystal structure of CHIR-AB1: a primordial avian classical Fc receptor. J Mol Biol 381: 1012-1024.

8. Taylor AI, Fabiane SM, Sutton BJ, Calvert RA, et al. (2008): The crystal structure of an avian IgY-Fc fragment reveals conservation with both mammalian IgG and IgE. Biochemistry 48: 558-562.

9. Herr AB, Ballister ER, Bjorkman PJ, et al. (2003): Insights into IgA-mediated immune responses from the crystal structures of human FceRI and its complex with IgA1-Fc. Nature 423: 614-620.

10. Viertlboeck BC, Schweinsberg S, Hanczaruk MA, et al. (2007): The chicken leukocyte receptor complex encodes a primordial, activating, high-affinity IgY Fc receptor. Proc Natl Acad Sci U S A 104: 11718-11723.

11. Taylor AI, Sutton BJ, Calvert RA (2010): Mutations in an avian IgY-Fc fragment reveal the locations of monocyte Fc receptor binding sites. Dev Comp Immunol 34: 97-101.

12. Murai A, Murota R, Doi K, et al. (2013): Avian IgY is selectively incorporated into the egg yolks of oocytes by discriminating $\mathrm{Fc}$ amino acid residues located on the $\mathrm{Cu} 3 / \mathrm{Cu} 4$ interface. Dev Comp Immunol 39: 378-387. 